\title{
JUSTIÇA DO TRABALHO E A EFETIVAÇÃO DE DIREITOS SOCIAIS NA ATUALIDADE
}

\section{JUSTICE OF WORK AND THE EFFECTIVENESS OF SOCIAL RIGHTS ON CURRENT TIMES}

\section{Vanessa Santos do Canto}

Resumo: Este trabalho discutirá a atual decisão do Supremo Tribunal Federal (STF) no âmbito da Ação de Descumprimento por Omissão (ADO) 26 e o Mandado de Injunção (MI) 4473, no que se refere à equiparação do crime de LGBTFOBIA ao crime de racismo. Em primeiro lugar discute as três hipóteses elaboradas pelo Ministro Celso de Mello, no que se refere à omissão legislativa, ao conceito de LGBTFOBIA e à prescrição da persecução penal. Em segundo lugar, aborda alguns estudos que têm demonstrado algumas dificuldades no que se refere à criminalização do "racismo", no âmbito da ação estatal e seus possíveis rebatimentos no Direito do Trabalho, sobretudo, no que se refere ao princípio do jus postulandi que é um dos princípios que garantem a autonomia deste ramo do direito. O referencial de pesquisa é centrado no institucionalismo histórico, notadamente, o de influência pós-estruturalista, centrado nas análises de Michel Foucault e Gilles Deleuze. O método de pesquisa é centrado na análise de jurisprudência do STF. O objetivo da pesquisa consiste na análise de alguns possíveis efeitos da "Reforma Trabalhista" realizada no ano de 2017, por meio de decisão do STF que reformulou a "Teoria do Risco" e, que, possivelmente "impactou" a "Teoria da Empresa", o Código de Defesa do Consumidor e a atuação do Ministério Público e da Defensoria Pública.

Palavras-chave: Equiparação. Reconhecimento. LGBTFOBIA. Racismo. Direito do Trabalho.

Abstract: This paper will discuss the current ruling of the Federal Supreme Court (STF) under the Default Omission Action (ADO) 26 and the Injunction Warrant (MI) 4473 regarding the equation of LGBTFOBIA crime with racism. Firstly, it discusses the three hypotheses made by Minister Celso de Mello regarding legislative omission, the concept of LGBTFOBIA and the prescription of criminal prosecution. Secondly, it addresses some studies that have shown some difficulties with regard to the criminalization of "racism" in the context of state action and its possible rebounds in labor law, especially as regards the principle of jus postulandi which is one of the principles that guarantee the autonomy of this branch of law. The research framework is centered on historical institutionalism, notably that of poststructuralist influence, centered on the analyzes of Michel Foucault and Gilles Deleuze. The research method is centered on the analysis of jurisprudence of the Supreme Court.

\footnotetext{
"Doutoranda em Teoria do Estado e Direito Constitucional pela PUC-Rio. Mestre em Serviço Social e graduada em Direito pela Pontifícia Universidade Católica do Rio de Janeiro (PUC-Rio).
} 
The objective of the research is to analyze some possible effects of the "Labor Reform" carried out in 2017, by means of an STF decision that reformulated the "Risk Theory" and that possibly "impacted" the "Company Theory". , the Consumer Protection Code and the performance of the Public Prosecution Service and the Public Defender's Office.

Keywords: Equalization. Recognition. LGBTFOBIA. Racism. Labor Law. 


\section{INTRODUÇÃO}

Este trabalho discutirá a atual decisão do Supremo Tribunal Federal (STF) no âmbito da Ação de Descumprimento por Omissão (ADO) 26 e o Mandado de Injunção (MI) 4473, no que se refere à equiparação do crime de LGBTFOBIA ao crime de racismo.

Em primeiro lugar discute as três hipóteses elaboradas pelo Ministro Celso de Mello, no que se refere à omissão legislativa, ao conceito de LGBTFOBIA e à prescrição da persecução penal. Em segundo lugar, aborda alguns estudos que têm demonstrado algumas dificuldades no que se refere à criminalização do "racismo", no âmbito da ação estatal e, os possíveis "rebatimentos" no âmbito da decisão "monocrática" do Ministro Gilmar Mendes no quando da análise do Mandado de Segurança (MS) 36392, que "suspendeu" a decisão do Tribunal de Contas da União (TCU) para manter o andamento do procedimento do edital que previa a possibilidade de contratação de "egressos" do "sistema prisional" por meio da modalidade de "pregão" eletrônico por parte do Instituto de Pesquisa Econômica Aplicada (IPEA).

O referencial de pesquisa é centrado no institucionalismo histórico, notadamente, o de influência pós-estruturalista, centrado nas análises de Michel Foucault e Gilles Deleuze. O intuito é discutir as "teorias do reconhecimento" desde a perspectiva pós-estruturalista francesa. A abordagem frankfurtiana será discutida de maneira "mediata". O método de pesquisa é centrado na análise de jurisprudência do Supremo Tribunal Federal (STF).

O objetivo do trabalho consiste na análise de alguns possíveis efeitos da "Reforma Trabalhista" realizada no ano de 2017, por meio de decisão do STF que reformulou a "Teoria do Risco" e, que, possivelmente "impactou" a "Teoria da Empresa", o Código de Defesa do Consumidor (CDC) e a atuação do Ministério Público e da Defensoria Pública.

As recentes decisões dos Tribunais Superiores têm possibilitado perceber mudanças significativas no que se refere ao discurso "racialista" que fundamenta as instituições do Estado brasileiro, notadamente, quanto ao Direito do Trabalho que, 
tem sido discutido quanto aos aspectos materiais, mas pouco discutido quantos aos aspectos "processuais".

\section{2 "EQUIPARAÇÃO" OU "RECONHECIMENTO"? OMISSÃO LEGISLATIVA NO ATIVISMO JUDICIAL}

No dia 13/06/2019, o STF equiparou os crimes de homofobia e de transfobia (denominados de LGBTFOBIA) ao crime de racismo. Por maioria, a Corte reconheceu a mora do Congresso Nacional para incriminar atos atentatórios a direitos fundamentais dos integrantes da comunidade LGBT. Os ministros Celso de Mello, Edson Fachin, Alexandre de Moraes, Luís Roberto Barroso, Rosa Weber, Luiz Fux, Cármen Lúcia e Gilmar Mendes votaram pelo enquadramento da homofobia e da transfobia como tipo penal definido na Lei do Racismo (BRASIL, 1989) até que o Congresso Nacional edite lei sobre a matéria.

Nesse ponto, ficaram vencidos os ministros Ricardo Lewandowski e Dias Toffoli, por entenderem que a conduta só pode ser punida mediante lei aprovada pelo Legislativo. O ministro Marco Aurélio não reconhecia a mora.

Em seguida, o ministro Ricardo Lewandowski reconheceu a mora legislativa e a necessidade de dar ciência dela ao Congresso Nacional a fim de que seja produzida lei sobre o tema. No entanto, não enquadra a homofobia e a transfobia na Lei do Racismo. Para Lewandowski, é indispensável à existência de lei para que seja viável a punição penal de determinada conduta, em atenção ao princípio da "reserva legal".

Por maioria, o Plenário aprovou a tese proposta pelo relator da ADO, ministro Celso de Mello, formulada em três pontos.

O primeiro prevê que, até que o Congresso Nacional edite lei específica, as condutas homofóbicas e transfóbicas, reais ou supostas, se enquadram nos crimes previstos na Lei 7.716/2018 e, no caso de homicídio doloso, constitui circunstância que o qualifica, por configurar motivo torpe.

No segundo ponto, a tese prevê que a repressão penal à prática da homotransfobia não alcança nem restringe o exercício da liberdade religiosa, desde que tais manifestações não configurem discurso de ódio. 
Finalmente, a tese estabelece que o conceito de racismo ultrapassa aspectos estritamente biológicos ou fenotípicos e alcança a negação da dignidade e da humanidade de grupos vulneráveis. Ficou vencido o ministro Marco Aurélio.

A decisão do STF que equiparou os crimes de homofobia, de transfobia ao crime de racismo na Ação de Inconstitucionalidade por Omissão (ADO) 26 e no Mandado de Injunção (MI) 4473 mostra que o tema deve ser discutido com maior atenção. O problema da persecução é questão fundamental nesta discussão ${ }^{1}$.

A decisão mostra que a omissão acerca da tipificação abre espaço para uma imprescritibilidade da persecução da conduta da "vítima", no que se refere ao exercício da sexualidade. Gênero não está separado do conceito de sexualidade e de raça. A filósofa e bióloga Donna Haraway, nos lembra desta questão ao discutir o conceito no "mundo do trabalho" desde uma perspectiva marxista. (HARAWAY, 2004).

No entanto, alguns estudos têm demonstrado algumas dificuldades no que se refere à criminalização do "racismo" (FERREIRA, 2012; GALDINO, BERNARDINO-COSTA, 2004; PIRES, 2016) no âmbito da ação estatal. Então, quais serão as possíveis tendências dos efeitos desta decisão no que se refere ao Direito do Trabalho?

Essa discussão é relevante tendo em vista o problema da equiparação dos crimes de homofobia, de transfobia, denominados de "LGBTFOBIA" ao crime de racismo ${ }^{2}$. Porque, sabemos, que os crimes de racismo, mesmo com a equiparação à injúria racial, não são submetidos à condenação. Outro problema é a imprescritibilidade da persecução penal. "Persecutio criminis ad aeternum"? "So what"? O problema é, ainda, o "Baile de gaiola na vida de gaiola".

Qual é a parte maldita? Teremos condições de saber de quem será o interesse de agir? Não devemos esquecer que a reforma processual do Código de Processo Civil e de Processo Penal instituiu importantes alterações no que se refere à intervenção de terceiros e ao papel do Ministério Público nas ações incondicionadas à representação. Além disso, qual é o "real" papel do Ministério

\footnotetext{
${ }^{1}$ Também é importante ressaltar o posicionamento políticos dos (as) antropólogos (as) negros (as) acerca do Pacote Anticrime proposto por Sérgio Moro.

${ }^{2}$ O julgamento da Ação Direta de Inconstitucionalidade por Omissão (ADO) 26, de relatoria do ministro Celso de Mello, e do Mandado de Injunção (MI) 4733, relatado pelo ministro Edson Fachin, foi concluído na tarde desta do dia 13/06/2019.
} 
Publico na atualidade? As recentes decisões dos tribunais superiores praticamente "desintegraram" a conexão "lei" e "processo" possibilitada pelo Código de Defesa do Consumidor $(C D C)$ e, ainda, não foram adequadamente analisados os efeitos dessas decisões no âmbito da atuação do Ministério Público brasileiro ${ }^{3}$.

Então, devemos. Sim, esse é o verbo "devemos" lembrar que o institucionalismo é parte maldita que não para de nos perscrutar. Quando dos debates iniciais acerca da implementação e execução das ações afirmativas no ensino superior brasileiro, as denominadas "cotas raciais", essa era a questão "maldita". A palavra "institucionalismo" pouco foi utilizada. Mas estava "presente" em quase todos os debates. Nesse sentido, o "problema sociológico mais profundo consiste então em buscar qual é então esta outra instância da qual dependem diretamente as formas sociais de satisfação das tendências". (DELEUZE, 2004, p. 135).

\section{3 "SISTEMA CARCERÁRIO" E "PREGÃO ELETRÔNICO", LGBTFOBIA E RACISMO: DILEMAS DO DIREITO DO TRABALHO?}

Em primeiro lugar, o que entendemos por tendência? Qual é o referencial teórico? Utilizamos o conceito de tendência desde a perspectiva elaborada por Gilles Deleuze, considerado um dos principais filósofos ligados ao pós-estruturalismo francês.

Ao discutir a relação existente entre "instintos" e "instituições", Deleuze (2004) antecipa algumas das discussões importantes que serão desenvolvidas no âmbito do denominado institucionalismo histórico.

No institucionalismo histórico, as instituições são definidas pelos autores, como:

Como os teóricos do institucionalismo histórico definem instituição? De modo global, como os procedimentos, protocolos, normas e convenções oficiais e oficiosas inerentes à estrutura organizacional da comunidade política ou da economia política. Isso se se estende das regras de uma

\footnotetext{
${ }^{3}$ O Supremo Tribunal Federal (STF) decidiu no dia 30/08/2018, que é lícita a terceirização em todas as etapas do processo produtivo, seja meio ou fim. Ao julgar a Arguição de Descumprimento de Preceito Fundamental (ADPF) 324 e o Recurso Extraordinário (RE) 958252, com repercussão geral reconhecida, sete ministros votaram a favor da terceirização de atividade-fim e quatro contra. O STF também decidiu no dia 25/05/2019, acerca da contratação de egressos do sistema prisional Mandado de Segurança (MS) 36392.
} 
ordem constitucional ou dos procedimentos habituais de funcionamento de uma organização até às convenções que governam o comportamento dos sindicatos ou as relações entre bancos e empresas. Em geral, esses teóricos têm a tendência a associar as instituições às organizações e às regras ou convenções editadas pelas organizações formais. (HALL, TAYLOR, 2003, p. 196).

Porque a definição de instituições apresentada por Gilles Deleuze e discutida de maneira implícita por Michel Foucault está próxima às características do institucionalismo histórico, quais sejam:

Com relação às outras escolas aqui examinadas, quatro características próprias àquela que acabamos de descrever são relativamente originais. Em primeiro lugar, esses teóricos tendem a conceituar a relação entre as instituições e o comportamento individual em termos muito gerais. Segundo, elas enfatizam as assimetrias de poder associadas ao funcionamento e ao desenvolvimento das instituições. Em seguida, tendem a formar uma concepção do desenvolvimento institucional que privilegia as trajetórias, as situações críticas e as consequências imprevistas. Enfim, elas buscam combinar explicações da contribuição das instituições à determinação de situações políticas com uma avaliação da contribuição de outros tipos de fatores, como as ideias, a esses mesmos processos. (HALL, TAYLOR, 2003, p. 196).

Mas, qual é a definição de instituições apresentada por Gilles Deleuze?

Os termos instinto e instituição são empregados para designar, essencialmente, procedimentos satisfação. Às vezes, reagindo por natureza a estímulos externos, o organismo retira do mundo os elementos de satisfação de suas tendências e de suas necessidades, elementos que, para diferentes os animais, formam mundos específicos. Outras vezes, instituindo um mundo original entre suas tendências e o mundo exterior, 0 sujeito elabora meios de satisfação artificiais, meios que liberam 0 organismo da natureza ao submetê-lo a outra coisa e que transformam a própria tendência ao introduzi-la em um novo meio; é verdade que o dinheiro livra da fome, com a condição de se tê-lo, e que o casamento poupa do trabalho de se procurar um parceiro, mas traz consigo outras obrigações. Isto quer dizer que toda experiência individual supõe, como um a priori, a preexistência de um meio no qual a experiência é levada a cabo, meio específico ou meio institucional. $O$ instinto e a instituição são as duas formas organizadas de uma satisfação possível. (DELEUZE, 2004, p. 134).

O conceito de "tendência" é capaz de mostrar uma relação existente acerca de uma estrutura previamente existente e as alterações produzidas pelas práticas institucionais desenvolvidas ao longo do tempo. Neste sentido, interessa-nos as práticas produzidas no âmbito do ativismo judicial ou judicialização da política. (VIANNA; BURGOS; SALLES, 2007). 
Neste sentido, as decisões do Supremo Tribunal Federal são capazes de modificar as estruturas sociais ao longo do tempo. Notadamente, por força de institutos jurídicos, tais como, a repercussão geral, mas também em razão de algumas decisões terem efeitos erga omnes em face de outras instituições.

O Supremo Tribunal Federal (STF) decidiu no dia 30 de agosto de 2018, na 1ํ- Turma, que é lícita a terceirização em todas as etapas do processo produtivo, seja meio ou fim, ao julgar a Arguição de Descumprimento de Preceito Fundamental (ADPF) 324 e o Recurso Extraordinário (RE) 958252, com repercussão geral reconhecida. Sete ministros votaram a favor da terceirização de atividade-fim e quatro votaram contra.

A tese de repercussão geral aprovada no RE foi a seguinte: afirma que "é licita a terceirização ou qualquer outra forma de divisão do trabalho entre pessoas jurídicas distintas, independentemente do objeto social das empresas envolvidas, mantida a responsabilidade subsidiária da empresa contratante".

O Ministro Celso Mello a e Ministra Carmen Lúcia afirmaram que eventuais abusos cometidos na terceirização devem ser reprimidos pontualmente, "sendo inadmissível a criação de obstáculos genéricos a partir da interpretação inadequada da legislação constitucional e infraconstitucional em vigor, que resulte na obrigatoriedade de empresas estabelecidas assumirem a responsabilidade por todas as atividades que façam parte de sua estrutura empresarial".

A decisão do STF exige algumas considerações acerca da denominada "Teoria da Empresa". Qual é o objetivo de uma empresa? Qual é a "função social" da empresa? Por que essas indagações são relevantes? Em primeiro lugar, não podemos esquecer que a crise do sistema fordista, fundado na indústria entrou em crise desde a década de 1970, com a transformação do Sistema Breton Woods e a crise nos países exportadores de petróleo. Essa foi uma das causas da modificação na estrutura da legislação que assegura a relações empresariais.

Antes relações comerciais, disciplinadas pela Lei $n .^{\circ} 556$, de 25 de junho de 1850, denominado Código Comercial brasileiro. Sabemos que o ano de 1850 no Brasil é crucial para a política, a economia e as relações jurídicas brasileiras. Em primeiro lugar, mudança na gestão das cidades, notadamente com a afirmação do higienismo, as políticas sanitárias, transformações nas relações existentes entre 
escravizados, libertos e livres, sobretudo, com o aumento da escravidão urbana. (KARASCH, 2000; SANTOS, 2010).

Além disso, no ano de 1850 surge a legislação que possibilita a criação de cemitérios públicos, sob a gestão da Santa Casa de Misericórdia. O surgimento dos cemitérios públicos fez com que a Igreja Católica tivesse que passar a lutar no que se refere gestão da mão de obra nas cidades litorâneas durante o império. De que maneira era realizada essa gestão? Sob a forma de assistência hospitalar e fúnebre (KARASCH, 2000). A abolição do sistema escravocrata do Império e a proclamação da República impuseram novos desafios à gestão da mão de obra no Brasil, notadamente, após 1930, com a ascensão de Getúlio Vargas ao poder político, momento no qual o regime fordista se afirma no Brasil.

A teoria da empresa começa a ser discutida no Brasil, de maneira mais abrangente, principalmente, após o ano de 1964, no âmbito da ditadura militar instaurada aquele ano. A denominada "reforma bancária" instituída pelos militares e a participação do capital estrangeiro sob a forma de oligopólios que investiram na estruturação de um "parque industrial" para a produção de bens duráveis foi importantes fatores para questionar o Direito Comercial. O conceito de "mercancia" começa a ser substituído pelo de "consumidores". A ênfase deixa de ser nos produtos e passa a ser nos "adquirentes" de "bens" e "serviços" nas cidades.

Surgem "ilhas de modernidade" no âmbito de um Estado ainda marcado pela produção agroexportadora, mas com um parque industrial que possibilita a formação de um mercado de trabalho com um número significativo de trabalhadores que se "ajustam" aos princípios e às normas da relação de emprego, constantes na Consolidação das Leis de Trabalho (CLT).

Além disso, não podemos esquecer que a responsabilidade subsidiária tem sido muito discutida no âmbito do Direito do Trabalho, notadamente, desde o ano de 1993, quando foi editada a Súmula 331, do Superior Tribunal do Trabalho (TST), em razão das fraudes trabalhistas. O "esvaziamento" patrimonial das empresas àquela época era causa de preocupação dos juristas, pois dificultava a fase de execução do processo trabalhista que tramitavam na Justiça do Trabalho.

Interessante notar, ainda, que, um dos princípios do Direito do Trabalho, que caracterizam a relação de emprego, qual seja, a não eventualidade, tenha sido 
interpretado dessa forma. De princípio que caracteriza a relação de emprego talvez tenha se tornado uma espécie de "medidor" de atos ilícitos no que se refere à caracterização do contrato de trabalho. Dessa forma, não há que se falar de "obstáculo genérico", eis que os princípios constitucionais do trabalho são garantias materiais e processuais para assegurar aos trabalhadores o exercício dos "direitos trabalhistas". Além disso, a Consolidação das Leis do Trabalho (CLT) é compilação de normas especiais que caracterizam a "autonomia" do Direito do Trabalho enquanto "ramo" do Direito.

O ministro Celso de Mello apontou que o movimento na Justiça Trabalhista, sobretudo com a proliferação de demandas coletivas para discutir a legalidade da terceirização, implica redução das condições de competitividade das empresas. "O custo da estruturação de sua atividade empresarial aumenta e, por consequência, o preço praticado no mercado de consumo também é majorado, disso resultando prejuízo para sociedade como um todo, inclusive do ponto de vista da qualidade dos produtos e serviços disponibilizados", ponderou.

O argumento do Ministro Celso Mello parece ignorar dois aspectos importantes. Em primeiro lugar, a Emenda Constitucional n. ${ }^{\circ} 45$, de 30 de dezembro de 2004 (EC n. ${ }^{\circ}$ 45/2004), denominada Reforma do Judiciário. Essa emenda constitucional, dentre outras questões, instituiu o denominado "princípio da celeridade processual" que tem por objetivos, quase sejam, ampliar o acesso ao Poder Judiciário e resolver as demandas de maneira mais célere. Essa inclusive foi um dos fundamentos para a elaboração da Lei n. ${ }^{\circ} 11.419$, de 19 de dezembro de 2006, denominada "Lei do Processo Eletrônico".

Outro aspecto importante se refere à própria Teoria da Empresa, qual seja o empresário deve assumir aquilo que os teóricos denominam de riscos do negócio, qual seja, o ônus com o custo da produção. Essa é a principal característica da denominada "Teoria do Risco", que constitui a "Teoria da Empresa", ou, ainda, o problema da "responsabilidade empresarial". Esse, inclusive, consideramos a principal questão não discutida de maneira adequada nas decisões da ADPF $324 \mathrm{e}$ no RE 958252.

Por quê? Porque a "Teoria do Risco" do negócio ou da atividade é um dos principais núcleos da responsabilidade da Lei n. ${ }^{\circ} 8.078$, de 11 de setembro de 1990, 
denominado de "Código de Defesa do Consumidor" (CDC). Além disso, o CDC é um dos microssistemas que articulam normas de direito material e de direito processual no ordenamento jurídico brasileiro. Uma das tendências legislativas dos anos 1990. Apresenta, no art., 81, a definição dos direitos coletivos, difusos e individuais homogêneos.

\begin{abstract}
Art. 81. A defesa dos interesses e direitos dos consumidores e das vítimas poderá ser exercida em juízo individualmente, ou a título coletivo.

Parágrafo único. A defesa coletiva será exercida quando se tratar de:

I - interesses ou direitos difusos, assim entendidos, para efeitos deste código, os transindividuais, de natureza indivisível, de que sejam titulares pessoas indeterminadas e ligadas por circunstâncias de fato;

II - interesses ou direitos coletivos, assim entendidos, para efeitos deste código, os transindividuais, de natureza indivisível de que seja titular grupo, categoria ou classe de pessoas ligadas entre si ou com a parte contrária por uma relação jurídica base;

III - interesses ou direitos individuais homogêneos, assim entendidos os decorrentes de origem comum.
\end{abstract}

No art. 82, dispõe acerca dos legitimados para propor as ações coletivas, na área consumerista. Mas, importante notar que a definição dos direitos materiais previstos no CDC, impacta a propositura de ações coletivas e ações civis públicas por parte do Ministério Público e Sindicatos, na área trabalhista.

Art. 82. Para os fins do art. 81, parágrafo único, são legitimados concorrentemente: (Redação dada pela Lei no 9.008, de 21.3.1995); (Vide Lei no 13.105, de 2015); (Vigência).

I - o Ministério Público,

II - a União, os Estados, os Municípios e o Distrito Federal;

III - as entidades e órgãos da Administração Pública, direta ou indireta, ainda que sem personalidade jurídica, especificamente destinados à defesa dos interesses e direitos protegidos por este código;

IV - as associações legalmente constituídas há pelo menos um ano e que incluam entre seus fins institucionais a defesa dos interesses e direitos protegidos por este código, dispensada a autorização assemblar.

[...]

$\mathrm{Na}$ justificativa do voto, o Ministro Celso Mello, destacou, ainda, dados estatísticos que mostram o aumento de vagas no mercado formal em decorrência do aumento da terceirização em empresas dos mais diversos segmentos econômicos. Afirmou, que: "O impedimento absoluto da terceirização trará prejuízos ao trabalhador, pois certamente implicará a redução dos postos de trabalho formal criados em decorrência da ampliação da terceirização nos últimos anos". 
O argumento de que se trata de impedimento "absoluto" acerca das terceirizações não deve prosperar. Pois, já o afirmamos antes, a construção jurisprudencial do Tribunal Superior do Trabalho (TST), através do Enunciado 331 permitia a terceirização de atividade-atividade, notadamente nas áreas de limpeza e conservação. Além disso, a terceirização também era prevista por meio de cooperativas de trabalho e as Organizações Sociais da Saúde (OSS), por exemplo, na área da saúde desde meados da década de 1995, quando da implementação do Plano Diretor de Reforma do Aparelho do Estado (PDRE-MARE).

A presidente do Supremo destacou que a terceirização não é a causa da precarização do trabalho nem viola por si só a dignidade do trabalho. "Se isso acontecer, há o Poder Judiciário para impedir os abusos. Se não permitir a terceirização garantisse por si só o pleno emprego, não teríamos o quadro brasileiro que temos nos últimos anos, com esse número de desempregados", salientou.

Além disso, a questão que consideramos relevante se refere à diferença existente entre "ato ilícito" e "abuso". A definição de ato ilícito está relacionada à Teoria Geral do Direito e definido enquanto ato praticado contrário à lei. A definição de ato ilícito está previsto no art. 186, do Código Civil de 2002: "Aquele que, por ação ou omissão voluntária, negligência ou imprudência, violar direito e causar dano a outrem, ainda que exclusivamente moral, comete ato ilícito".

Após a entrada em vigor do Código Civil de 2002, a "Teoria do abuso de Direito" tem causado controvérsias no âmbito doutrinário. Está previsto no art. 187: "Também comete ato ilícito o titular de um direito que, ao exercê-lo, excede manifestamente os limites impostos pelo seu fim econômico ou social, pela boa-fé ou pelos bons costumes".

Então, a noção de "abuso" está relacionada à extrapolação no que se refere à utilização da norma em vigor no ordenamento jurídico. "O abuso de direito consiste no uso imoderado do direito subjetivo, de modo a causar dano a outrem". (AMARAL, 2003, p. 550).

O principal aspecto discutido no que se refere ao "abuso de direito" é o problema da culpa, cerne da discussão acerca da responsabilidade anteriormente discutida. A posição da Ministra do STF é a da necessidade da comprovação da culpa, tendo em vista que advoga a responsabilidade subsidiária, inclusive na atual 
conjuntura, na qual admitem os Tribunais Superiores, a terceirização de "atividadefim" das empresas.

Dessa forma, apresentarei alguns possíveis efeitos da decisão monocrática em sede de liminar, proferida pelo Ministro do Supremo Tribunal Federal, Gilmar Mendes, no Mandado de Segurança (MS) 36392, impetrado pelo Instituto de Pesquisas Econômicas Aplicadas (IPEA), afastando a decisão do Tribunal de Contas da União (TCU), que havia suspendido o "pregão eletrônico" previsto na Lei n. ${ }^{\circ} 8.666 / 93$.

O "pregão eletrônico" foi utilizado pelo IPEA para a contratação de empresa prestadora de serviços de apoio administrativo que deverá empregar percentual de pessoas presas ou egressas do sistema prisional. O "pregão eletrônico" está previsto no Decreto $n^{\circ}$ 5.450, de 31/05/2005, para a aquisição de bens e serviços comuns por meio da utilização de recursos de Tecnologia da Informação, ou seja, por meio de comunicação pela Internet:

\begin{abstract}
Art. $1^{\circ}$. A modalidade de licitação pregão, na forma eletrônica, de acordo com o disposto no $\S 1^{\circ}$ do art. $2^{\circ}$ da Lei $n^{\circ} 10.520$, de 17 de julho de 2002, destina-se à aquisição de bens e serviços comuns, no âmbito da União, e submete-se ao regulamento estabelecido neste Decreto.

Parágrafo único. Subordinam-se ao disposto neste Decreto, além dos órgãos da administração pública federal direta, os fundos especiais, as autarquias, as fundações públicas, as empresas públicas, as sociedades de economia mista e as demais entidades controladas direta ou indiretamente pela União.

Art. $2^{\circ}$. O pregão, na forma eletrônica, como modalidade de licitação do tipo menor preço, realizar-se-á quando a disputa pelo fornecimento de bens ou serviços comuns for feita à distância em sessão pública, por meio de sistema que promova a comunicação pela internet.
\end{abstract}

O edital n. ${ }^{\circ}$ 9/2018 do Lote 03 (três) do Pregão Eletrônico determina que a empresa vencedora tenha de empregar mão de obra formada por pessoas presas ou egressos do sistema prisional e, para isso, deve apresentar declaração emitida Vara de Execuções Penais (VEP) de que dispõe de pessoas presas aptas à execução de trabalho externo. Ocorre que, em representação formulada pela vencedora do certame, ministro do TCU considerou plausível o argumento de que essa última exigência extrapolaria a documentação prevista no artigo 28 da Lei de Licitações. (BRASIL, 1993).

No Mandado de Segurança, o IPEA alega que o pregão reproduz regra

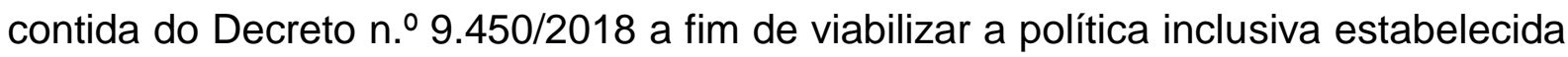


pela Lei n. ${ }^{\circ}$ 13.500/2017, permitindo a contratação e a ressocialização de pessoas presas ou egressas do sistema prisional que, na avaliação da VEP, estejam aptas à execução de trabalho externo. O IPEA pediu ao Supremo a suspensão dos efeitos da decisão questionada, ressaltando que o contrato anterior venceu em fevereiro deste ano.

A decisão proferida no dia 15 de abril de 2019, pelo ministro Gilmar Mendes, relator do Mandado de Segurança, é teleológica na medida em que considerou que verificou que a porque a interpretação de 0 artigo 28 da Lei de Licitações deve abranger todo o contexto da referida lei.

Verificou que a empresa entregou a declaração de que empregará pessoas presas ou egressas do sistema prisional, mas sem o documento emitido pela VEP, conforme exigência do pregão. O relator explicou que, com o objetivo de implementar política de ressocialização de presos e egressos, a Lei 13.500/2017 inseriu no artigo 40 da Lei de Licitações regra que permite à administração pública exigir da empresa contratada um percentual mínimo de mão de obra proveniente do sistema prisional, e o Poder Executivo Federal editou o Decreto 9.450/2018 para regulamentar a norma.

O Ministro, Gilmar Mendes, afirmou que a exigência prevista no edital atende ao princípio da legalidade (artigo 40 da Lei 8.666/1993) e à prevalência do interesse público e obedece aos princípios da impessoalidade e da seleção mais vantajosa para a administração.

Ele lembrou ainda que as normas do certame se dirigem a todos os concorrentes, e não seria razoável dispensar apenas uma das empresas da exigência de item previsto no edital, sob a pena de violar o princípio da igualdade. A Procuradoria Geral da República (PGR) manifestou-se pela "concessão da segurança". No dia 17 de maio de 2019, foi confirmada a decisão proferida na liminar, "concedendo a segurança", no Mandado de Segurança (MS) 36392.

Mas, quais são os possíveis efeitos dessa decisão no debate jurídico acerca das ações afirmativas com "recorte racial"? Qual seria a importância do conceito esboçado "campo de concentração do alguidar", notadamente no que se refere ao Direito Tributário? 
Em primeiro lugar, o IPEA é uma instituição de pesquisa que conhece a realidade acerca da implementação das políticas de ação afirmativa com "recorte racial" no Brasil. Desde a década de 1990, alguns pesquisadores demonstraram a dificuldade na gestão das políticas para a promoção do princípio da igualdade racial (HENRIQUES, 2001). As análises foram confirmadas após a primeira década do ano 2000 (IPEA, 2011; IPEA, 2014), principalmente após o "governo Lula".

Em segundo lugar, decisões do STF demonstram alguns problemas relativos aos limites da decisão do Ministro Gilmar Mendes. Por quê? Somos todos uns "pregos"? A Lei de Licitações tem sido interpretada de maneira "restritiva". "Combinada" com a interpretação acerca do rol do "Ministério do Trabalho". Além disso, persiste o problema relativo ao recolhimento dos tributos municipais que "incidem" na prestação de serviços, que também tem sido considerada "taxativa", não apenas "exemplificativa".

Qual é a importância dessas questões no que se refere às políticas públicas com "recorte racial" e a contratação de pessoas "egressas" do sistema prisional? Em primeiro lugar, o problema do acesso à justiça. Nos casos nos quais os trabalhadores tiverem que acessar a Justiça do Trabalho, quais direitos buscarão? Decisões acerca do rol que compõem atividades laborais previstas pelo Ministério do Trabalho indicam que são taxativas e não extensivas.

Quais as modalidades de recolhimento do tributo municipal? Não devemos esquecer que o Estado possui problemas de arrecadação há algum tempo. Essa é uma questão que remete ao problema relativo à relação processo versus procedimento, notadamente no que se refere à Lei n. 11.419, de 19 de dezembro de 2006, denominada lei do "processo eletrônico". Talvez, em breve, o sistema apresente alguma "pane".

Não devemos esquecer, ainda, que a maior parte da população prisional é composta por pessoas negras (incluindo um número crescente de mulheres negras). Apresentam baixa escolaridade e estão ligadas à base do denominado "crime organizado". (BRASIL, 2017). 


\section{CONSIDERAÇÕES FINAIS}

As transformações do capital representam novos desafios aos gestores públicos, sobretudo após a publicação da denominada lei do "processo eletrônico". Quais são as modalidades de "reparação" que serão implementadas no âmbito do Poder Executivo? Questão ainda não discutida pelos juristas na atualidade.

As ações afirmativas não foram capazes de modificar o perfil da população prisional brasileira. Quais são os efeitos na discussão acerca do trabalho da população negra, notadamente, após a elaboração do Estatuto da Igualdade Racial? Quais serão as contribuições políticas que essa decisão suscitará no que se refere à atuação, especialmente, dos diferentes segmentos do "movimento negro"?

Os atuais "fenômenos" sociais apresentam conflitos de força que parecem concentrar esforços que mistificam os fundamentos do discurso acerca da Teoria do Estado e, de maneira mediata do Direito do Trabalho, ramo do Direito Privado. E, a reforma ministerial realizada no ano de 2019 (Medida Provisória n. 870 e Decreto n. $.9 .660 / 19$ ), no âmbito do governo do atual Presidente da república, Jair Bolsonaro, talvez indique o retorno de algumas questões acerca do debate racial brasileiro que pareciam ter sido superadas.

O Ministério da Cultura foi transformado em Ministério da Cidadania. Voltamos aos primórdios da "Antropologia" kantiana? Voltaremos apenas a discutir "O preço da justiça" (VOLTAIRE, 2006) e "O problema da justiça" (KELSEN, 2011). Por quê? Por que parece que a "fazendinha" está em crise. Talvez digam que nunca existiu "fazenda". Que não aconteceu "casamento na roça". Que não existia "curral" eleitoral. Que não existiu "escravidão" no Brasil. Que não existiu "escravização" no Brasil. Que não existiram "escravocratas" no Brasil.

Então, qual memória do mundo restará? Por quê? Por que parece que teremos que "refrescar" a memória. Talvez digam que somente existiram oikos nomos. Que somente existiu o nomos da terra. "Favela, cultura e lazer"? Que comunidade que vem?

Quais são os efeitos dessa discussão nos tribunais superiores brasileiros na "contemporaneidade"? Parece que o discurso "racialista" tem perdido a força ao passo que as teorias da etnicidade têm adquirido mais notoriedade. 
Então, a equiparação dos crimes de homofobia e transfobia ao crime de racismo provavelmente irá impactar o Direito do Trabalho, notadamente, após a Reforma Trabalhista. Em primeiro lugar, o princípio do "jus postulandi” na Justiça do Trabalho. A crise da Teoria da empresa e da Teoria do Risco provavelmente impactará o direito Coletivo do Trabalho e a atuação do Ministério Público e as possibilidades de atuação da Defensoria Pública.

Em segundo lugar, a discriminação no mercado de trabalho talvez se acentue contra os homossexuais e a crise do princípio do "jus postulandi" talvez impacte o famoso brocardo jurídico trabalhista "vai procurar seus direitos na justiça". No nosso caso, na Justiça do Trabalho.

Em terceiro lugar, não podemos esquecer que a crise do "jus postulandi" que provavelmente começará a impactar os julgamentos da Justiça do Trabalho também impactará a historicamente discriminada população negra brasileira. Casa vez mais pessoas negras têm adensado o sistema carcerário brasileiro.

Quais serão os caminhos do Direito do Trabalho material e processual no âmbito das novas tendências que têm se delineado na atualidade? As teorias frankfurtianas que pareciam informar a Teoria do Direito, de maneira mais ampla parecem não estarem sendo capazes de explicar às tendências recentes das decisões dos Tribunais Superiores, notadamente, as decisões do Tribunal Superior do Trabalho (TST) e do Supremo Tribunal Federal (STF).

Dessa forma, devemos estar atentos aos impactos que essas mudanças terão de maneira mais ampla no que se refere ao princípio da autonomia que informar os ramos e disciplinas do Direito para que não sejamos apanhados por uma crise de maior amplitude no Direito do Trabalho e, na Teoria do Direito e na Teoria do Estado, de maneira mais geral.

Não podemos olvidar que a Reforma Trabalhista e a equiparação dos crimes de homofobia e transfobia ao crime de racismo atingirá uma pequena parcela da população brasileira. Não devemos esquecer que mais da metade da população brasileira é negra e, cada vez mais vem sendo registrado casos de racismo e intolerância religiosa no mercado de trabalho e no ambiente de trabalho, não obstante 0 acúmulo civilizatório das ações afirmativas que vêm sendo implementadas desde o final dos anos 1990. 
O acesso à Justiça é um desafio global. Mas, por razões históricas a Justiça do Trabalho brasileira deve ser alentada enquanto importante mecanismo de garantia e exercício dos direitos sociais. Os direitos humanos fundamentais devem pautar a ação do Estado, notadamente, no contexto político no qual nos encontramos. Atentemos para a comunidade que vem? Certamente.

\section{REFERÊNCIAS}

AMARAL, Francisco. Direito civil: introdução. 5. ed. Rio de Janeiro: Renovar, 2003.

BRASIL. Lei n. 7.716, de 5 de janeiro de 1989. Define os crimes resultantes de preconceito de raça ou de cor. Brasília, DF: Presidência da República, 1989.

Disponível em: http://www.planalto.gov.br/ccivil_03/leis/l7716.htm. Acesso em: 20 maio 2019.

BRASIL. Lei n. 8.666, de 21 de junho de 1993. Regulamenta o art. 37, inciso XXI, da Constituição Federal, institui normas para licitações e contratos da Administração Pública e dá outras providências. Brasília, DF: Presidência da República, 1993.

Disponível em: http://www.planalto.gov.br/ccivil_03/Leis/L8666cons.htm. Acesso em: 20 maio 2019.

BRASIL. Ministério da Justiça e Segurança Pública. Levantamento nacional de informações penitenciárias: INFOPEN Mulheres - junho de 2017. Organização de Marcos Vinícius Moura. Brasília, DF: Ministério da Justiça e Segurança Pública; Departamento Penitenciário Nacional, 2017.

DELEUZE, Gilles. Instintos e instituições. In: LAPOUJADE, David. A ilha deserta e outros textos. São Paulo: lluminuras, 2004. p. 134-137.

FERREIRA, Renato. Ações afirmativas: a questão das cotas. Rio de Janeiro: Impetus, 2012.

GALDINO, Daniela; BERNARDINO-COSTA, Joaze. Levando a raça a sério. Rio de Janeiro: DP\&A, 2004.

HALL, Peter A.; TAYLOR, Rosemary C. R. As três versões do neo-institucionalismo. Lua Nova, São Paulo, n. 58, p. 193-223, 2003.

HARAWAY, Donna. Gênero para um dicionário marxista: a política sexual de uma palavra. Cadernos Pagu, Campinas, n. 22, p. 201-246, 2004.

HENRIQUES, Ricardo. Desigualdade racial no Brasil: evolução das condições de vida na década de 90. Brasília, DF: IPES, 2001. 
INSTITUTO DE PESQUISA ECONÔMICA APLICADA. Nota técnica. Planejamento e financiamento das políticas de igualdade racial: possibilidades para o plano plurianual 2012-2015. Brasília, DF: Ipea, 2011.

INSTITUTO DE PESQUISA ECONÔMICA APLICADA. Relatório de pesquisa. Planejamento, orçamento e a promoção da igualdade racial reflexões sobre os planos plurianuais 2004-2007 e 2008-2011. Brasília, DF: Ipea, 2014.

KARASCH, Mary C. A vida dos escravos no Rio de Janeiro (1808-1850). São Paulo: Companhia das Letras, 2000.

KELSEN, Hans. O problema da justiça. 5. ed. São Paulo: Martins Fontes, 2011.

PIRES, Thula. Criminalização do racismo: entre política de reconhecimento e meio de legitimação do controle social sobre os negros. Brasília: Brado Negro, 2016.

SANTOS, Ynaê Lopes. Duas irmãs do atlântico. Rio de Janeiro: Ministério da Cultura, 2010.

VIANNA, Luiz Werneck; BURGOS, Marcelo Baumann; SALLES, Paula Martins. Dezessete anos de judicialização da política. Tempo soc., São Paulo, v. 19, n. 2, p. 39-85, nov. 2007. Disponível em: http://www.scielo.br/pdf/ts/v19n2/a02v19n2. Acesso em: 20/05/2019.

VOLTAIRE, François-Marie Arouet. O preço da justiça. São Paulo: Martins Fontes, 2006.

Recebido em 06/11/2019.

Aceito em 19/12/2019. 